\title{
9 Leaf Properties
}

The following quote typifies the variability among SouthWest leaves:

"That plants of the south-west should exhibit a variety of leaf types is not surprising. The features of interest are that:

1) Such widely divergent leaf types occur within single genera, and evidently most of them represent autochthonous [occurring at its place of origin] development;

2) Some of these leaf types are unique, not found elsewhere;

3) With all genera compared, there is such a high degree of convergent evolution; and

4) There is apparently easy reversibility in morphology.

Leaf morphology, a rapidly evolving feature, can exhibit sensitive adaptation for a particular habitat, although it may in some cases lag behind physiological adaptation, and various leaf types are equally successful in a given locality".

Sherwin Carlquist (1974) Island Biology. Columbia University Press, New York

The SouthWest flora has an exceptional array of leaf shapes and sizes, including phyllodes and cladodes. Leaf (or leaf-like) diversity is greatest among the most speciose shrub genera including Melaleuca, Acacia, Grevillea, Hakea, and Daviesia. Note that the Melaleuca complex now incorporates the SouthWest endemic genera Beaufortia, Calothamnus, Conothamnus, Eremaea, Phymatocarpus and Regelia (Edwards et al., 2010; Craven et al., 2014). The level of diversity is especially high in the hyperdiverse sandplain floras where co-occurrence is driven by niche differentiation, habitat filtering (species with similar ecological requirements co-occur more often than expected by chance), biogeographic history and phylogenetic clustering (Merwin et al., 2012). In addition, many adaptive solutions to the same soil nutrient levels, light intensities, air temperatures, winds and moisture regimes are feasible, creating a rich tapestry of form and function.

\subsection{Leaf Size}

Surviving the hot, dry summers of the SouthWest requires structural and physiological strategies that maximize leaf water-use efficiency (see Chapter 3) without compromising leaf heat resistance. These include a reduction in leaf size, an increase in mechanical strength (thicker cells, more fibrous tissue) and changes in leaf absorbance properties (e.g. presence of light-reflective hairs). The ability of a species to tolerate extreme summer temperature events will be determined by the interaction between leaf heat loads (i.e. rise in leaf temperature, a function of leaf size and transpiration rate), heat-storing capacity (a function of leaf thickness) and the degree of exposure to the prevailing environmental conditions (Groom et al., 2004). 
Most SouthWest scrub-heath species have leaves that can be categorised as leptophyllous ( $<25 \mathrm{~mm}^{2}$ in one-sided area), the smallest size class recognized (Table 9.1). Small areas both minimize leaf water loss and reduce the likelihood of excessive, and potentially lethal, leaf temperatures occurring during the hot summers. Leaf size and level of sclerophylly can vary considerably within a genus and even within a species from juvenile to adult leaves-heteroblasty (e.g. Hakea; Groom et al., 1997). H. trifurcata is unusual in its seasonal production of broad and needle leaves (seasonally recurrent heteroblasty) (Groom et al., 1994). Eucalypt woodlands and forests of the SouthWest have a higher percentage of broad-leaved species present in their understorey than the sandplain shrublands because they experience less exposure (more shade).

Table 9.1: Leaf traits (\%) of 429 vascular plant taxa (including 2 gymnosperms, 75 monocotyledons, 352 dicotyledons) at four sites containing kwongan vegetation ( $250 \mathrm{~km} \mathrm{~N}$ of Perth). Kwongan is an indigenous term for the low, heath-like sclerophyllous sandplain shrublands. Phyllodes and phylloclades are treated as leaves here though they are more like green stems in structure. Data collated from Pate et al., (1984).

\begin{tabular}{|c|c|c|c|c|}
\hline \multicolumn{5}{|l|}{ Leaf shape } \\
\hline Scale leaves & Needle-like & Strap-like & Dissected flat & Broad flat \\
\hline 11.4 & 26.3 & 36.6 & 8.3 & 17.5 \\
\hline \multicolumn{5}{|c|}{ Leaf size category $\left(\mathrm{cm}^{2}\right)$} \\
\hline Leptophyll & Nanophyll & Nano-microphyll & Microphyll & $\begin{array}{l}\text { Mesophyll } \\
\text { (and larger) }\end{array}$ \\
\hline$<0.25$ & $0.25-2$ & $2-12$ & $12-56$ & $56-180+$ \\
\hline 54.3 & 21.4 & 18.6 & 5.0 & 0.4 \\
\hline \multicolumn{5}{|c|}{ Leaf consistency } \\
\hline $\begin{array}{l}\text { Sclerophyll } \\
\text { (hard) }\end{array}$ & $\begin{array}{l}\text { Malacophyll } \\
\text { (soft) }\end{array}$ & Resinous & Succulent & No leaves \\
\hline 68.0 & 27.5 & 0.9 & 3.5 & 0.2 \\
\hline \multicolumn{5}{|l|}{ Leaf colour } \\
\hline Green & Green and white & White, hoary & $\begin{array}{l}\text { Glaucous } \\
\text { (grey, powdery) }\end{array}$ & Brown \\
\hline 69.7 & 8.1 & 1.9 & 10.7 & 9.6 \\
\hline \multicolumn{5}{|c|}{ Leaf life span (years) } \\
\hline$<1$ & 1 & $2-3$ & $4-5$ & $>5$ \\
\hline 20.7 & 40.8 & 35.6 & 1.9 & 1.0 \\
\hline
\end{tabular}



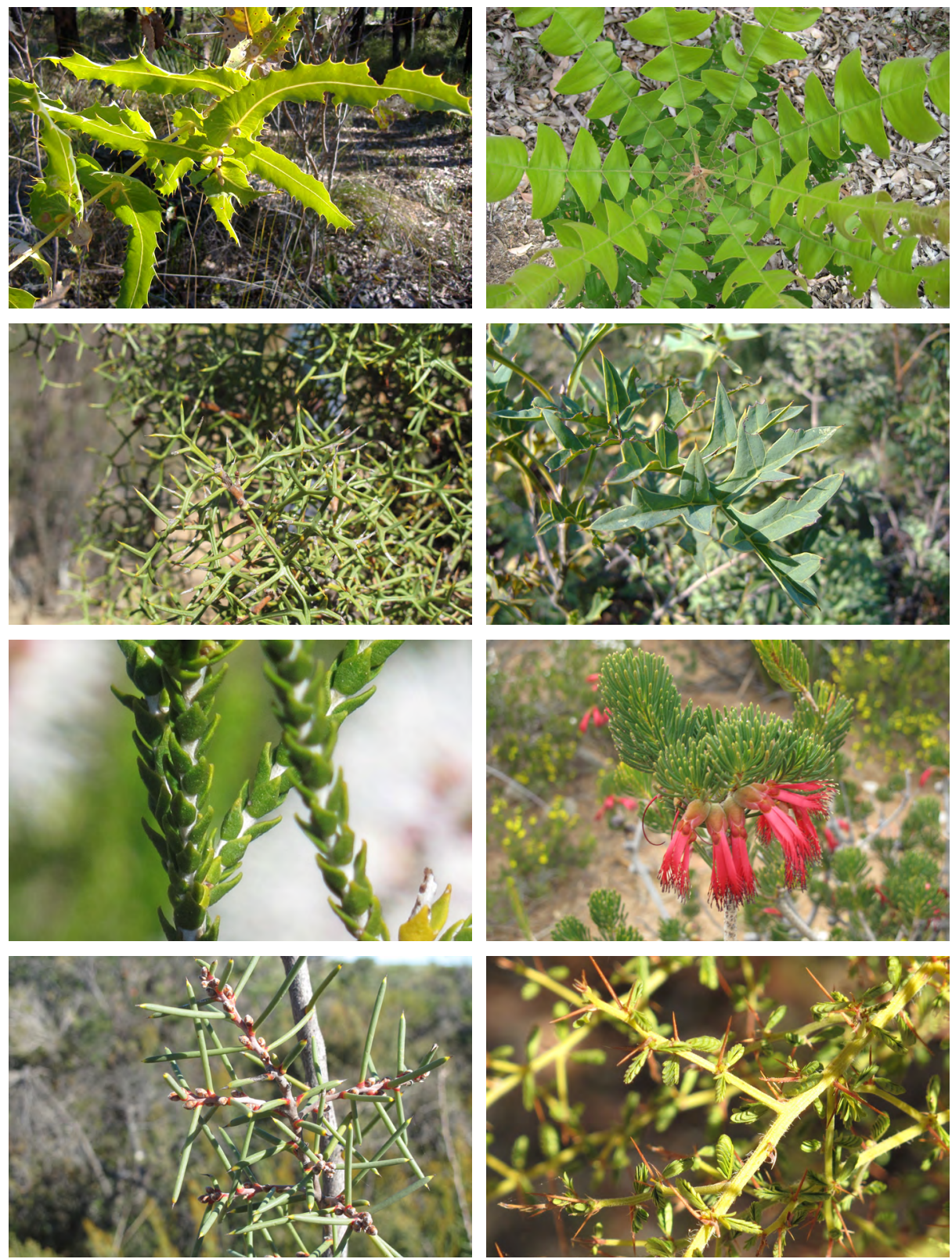

Fig. 9.1: Variability in leaf size, shape and texture of the shrub and tree species in the SouthWest flora. Species are (from top to bottom, left to right: Margins are sharply mucronated (pointed) on the leaves of Hakea amplexicaulis (Proteaceae), Banksia grandis (Proteaceae), Hakea horrida, Grevillea bipinnatifida (Proteaceae), Melaleuca huegelii (Myrtaceae), Calothamnus sanguineus (Mytaceae) and Hakea psilorrhyncha (Proteaceae) whereas the soft compound leaves of Acacia pulchella (Fabaceae) are subtended by sharp thorns (photo shows the pinnae of $A$. pulchella bipinnate leaves folded together in response to the summer drought). Leaves vary in length from $15 \mathrm{~cm}$ in $H$. amplexicaulis to $<5 \mathrm{~mm}$ in $M$. huegelii and in thickness from $0.5 \mathrm{~mm}$ in A. pulchella to $3 \mathrm{~mm}$ in $H$. psilorrhyncha. 


\subsection{Leaf Design}

In Mediterranean-type climates the degree of sunlight exposure and water accessibility during the hot, dry summer months are strong abiotic selective forces on the leaf design of extant species. Trade-offs between photosynthetic capability, water-use efficiency and leaf heat loading control leaf size and shape constrained by phylogenetic and lineage limits (Ackerly, 2004). Many SouthWest species inhabit landscapes with minimal or no shade and are therefore exposed to prolonged hot and dry summer conditions, and this has implications on leaf design, leaf arrangement on the stem (phyllotaxy) and leaf orientation.

\subsubsection{Reducing Summer Leaf Heat Loads}

Leaf shape and size are linked to photosynthetic rates and leaf thermotolerances (Knight \& Ackerly, 2002; 2003; Nicotra et al., 2008). Taxa with highly dissected, pinnate, lobed and serrated leaves (Fig. 9.1) typically have a greater photosynthetic tolerance of high temperatures, and dissipate heat quicker than if the leaf was entire (Nicotra et al., 2008), and thus are favoured in landscapes exposed to periods of prolonged high air temperatures. Where leaves (or phyllodes) are not dissected or lobed they may be orientated vertically as an alternative means of reducing heat loads (Smith et al., 1998) and protecting the photosynthetic process against excessive leaf temperatures when stomates close as a response to summer water stress.

Approximately a quarter of the SouthWest's woody shrub species possess needle-like leaves that are either single (e.g. Hakea psilorrhyncha) or highly dissected (e.g. H. horrida) (Fig. 8.1), and are typically highly spinescent at their apices. Leaf spines may not only serve as an anti-herbivore or granivore deterrent, but also assist in the dissipation of summer leaf heat loads. Needle leaves have a reduced surface area and an increased leaf thickness compared with broad leaves. Clusters of thick, minute (leptophyll-nanophyll) leaves (e.g. Melaleuca huegelii, Calothamnus sanguineus, Fig. 9.1) are another mechanism to minimize leaf heat loads. Thick leaves retain more thermal energy than co-occurring thinner leaves (Groom et al., 2004) and have a lower rate of change in leaf temperature (Jones, 1992). Leaf thickness has a dampening effect on heat absorption and irradiance damage avoidance (Leigh et al., 2012). The impact of increased thickness is greatest when other means of reducing leaf temperature (transpiration, reflectance or reduced size) are lacking (Leigh et al., 2012).

Needle-like leaves first appeared in SouthWest Banksia and Hakea species 14-15 Ma (He et al., 2011; T. He, unpublished data) during a period of aridification that marked the beginning of today's Nullarbor Plain. Extant needle-leaved species of the widespread genus Hakea are more likely to be found in landscapes with less reliable rainfall (the Wheatbelt and Mallee woodlands and heaths of the Esperance Plains), 
whereas broad-leaved species tend to occur where there is more reliable seasonal rainfall (e.g. Geraldton sandplains) or less extreme annual temperatures (e.g. the forested regions) (Groom \& Lamont, 1996).

\subsubsection{Heterophylly}

The Southwest flora is noted for the strong presence of heterophylly (different leaf types within a plant), mainly as a heteroblastic process with the juvenile leaves tending to be more mesomorphic and the adult leaves highly scleromorphic (Groom et al., 1997; Zotz et al., 2011). Heterophyllous traits may have evolved as part of a mimicry syndrome (e.g. Hakea trifurcata; Fig. 3.5) or they may serve to protect the plant directly from florivores and granivores when they flower and fruit (e.g. H. auriculata; Fig. 9.10; 9.11). In both cases, the highly-modified, protective leaves only appear once the plant starts to flower (Groom et al., 1994). In the Fabaceae, heteroblasty involves the initial production of simple or compound leaves transitioning to phyllodes or cladodes (Walker \& Pate, 1986; Forster \& Bonser, 2009), e.g. Daviesia horrida. In phyllodinous Acacia species (Fig. 9.2), the ontogenetic transition from (bi)pinnate compound leaves to phyllodes in the early seedling stage is viewed as evolutionarily redundant, reflecting the leaf form ancestry of the genus (Gardner et al., 2008). This includes a transitionary phase where successive leaves are produced with an expanding flattened petiole and a gradually reducing lamina of terminal leaflets until only the phyllode is formed (Kaplan, 1980; Fig. 9.2).

For species within section Pulchellae (e.g. Acacia pulchella; Fig. 9.2) the first two true leaves are pinnate and formed simultaneously, with opposite phyllotaxy (Guinet et al., 1980; Miller et al., 2003). Ontogeny whereby a pinnate leaf develops first, followed by bipinnate leaves, occurs in a range of taxonomic subgroups, including the majority of section Acacia (Miller et al., 2003; Murphy et al., 2010; Miller \& Miller, 2011; Miller et al., 2013). Heteroblasty in Acacia is considered non-adaptive (functionally neutral) because of the short timeframe between the formation of true leaves and phyllodes, all of which are present together in the first growing season (Zotz et al., 2011; Fig. 9.2). 

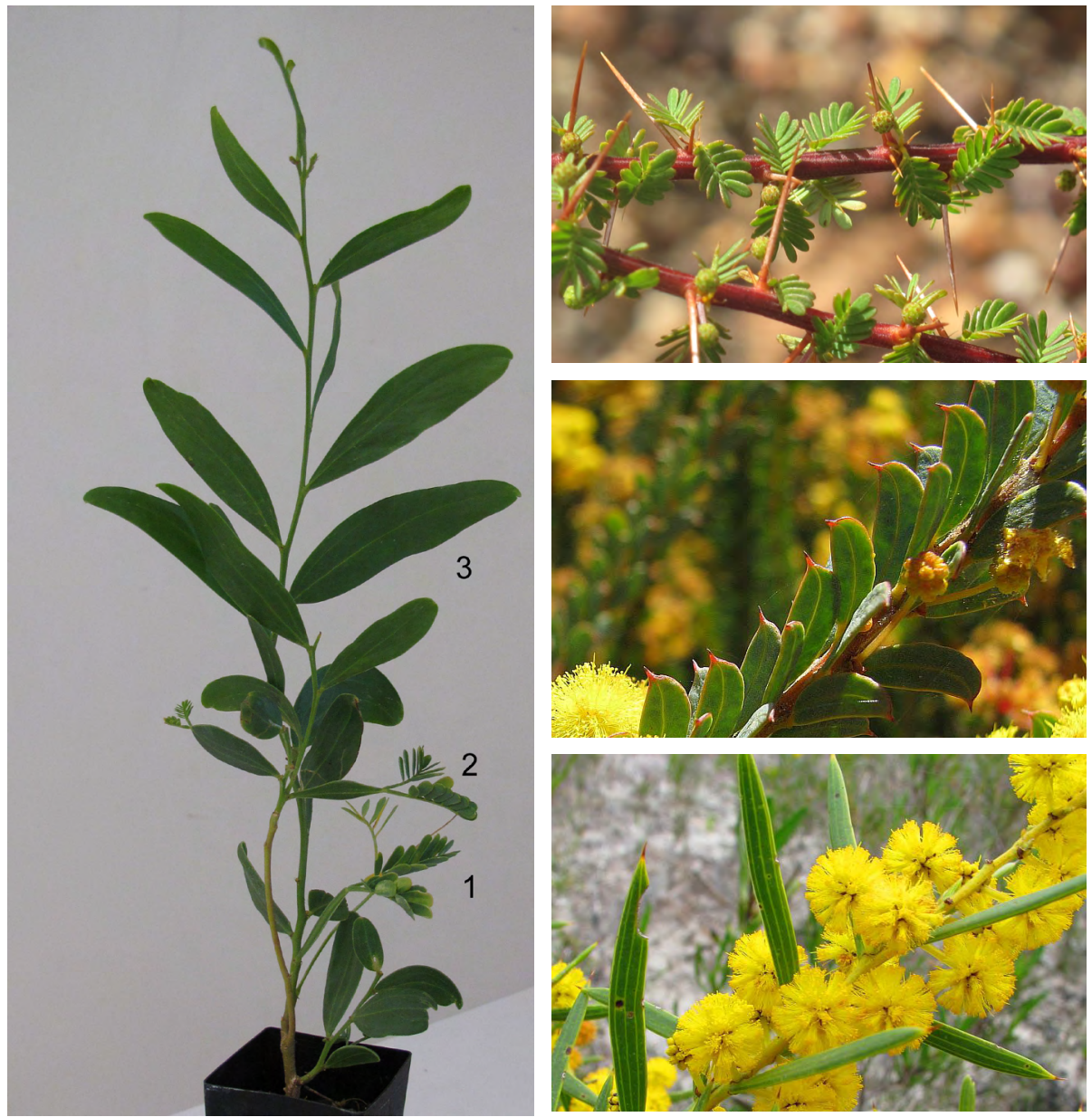

Fig. 9.2: (left) A heteroblastic Acacia (Fabaceae) seedling displaying the transition from pinnate leaves (1), to an intermediate stage (2) where compound leaves are subtended by a vertically-flattened petiole to the formation of phyllodes only (3). Seedling is $25 \mathrm{~cm}$ tall. (right) Selection of 'leaves' within the genus: (top) bipinnate leaves of $A$. pulchella each basal to a 12-mm-long thorn. This is a member of section Pulchellae that consists of species mostly in Western and Northern Australia that radiated 20-22 Ma (Miller et al., 2013). (middle) Vertically-orientated phyllodes of $A$. camptoclada with a prominent central vascular vein (uninerved) that ends in a blunt spine. Phyllode $15 \mathrm{~mm}$ long. (lower) Phyllodes of $A$. cochlearis with prominent 3-4 raised veins (trinerved). Phyllode $35 \mathrm{~mm}$ long. Photos of $A$. camptoclada and $A$. cochlearis provided by Esperance Wildflowers.

\subsection{Sclerophylly}

Sclerophylly refers to how tough, stiff or leathery a leaf is. Various indices of sclerophylly have been proposed. However, there is one simple measure that 
incorporates both morphological and structural aspects in our understanding of sclerophylly. This is leaf mass per area (LMA) that relates to how much structure (e.g. sclereids, cell wall thickening, palisade layers) is invested per unit area of projected (one-sided) leaf area (Groom \& Lamont, 1999). The more a leaf invests in strength and support, the more sclerophyllous it will be, resulting in an increase in LMA (Read et al., 2005). LMA is the product of leaf thickness and leaf density, representing different structural properties of the leaf (Witkowski \& Lamont, 1991; Niinemets, 2001; Poorter et al., 2009). The level of leaf toughness can also be measured directly and involves determining the amount of force required to fracture a leaf.

Southwestern Australia has some of the most nutrient-impoverished soils in the world (Lamont, 1995; Groom \& Lamont, 2010). This can be attributed to its history of geological stability over the last 100 million years with continual leaching of the soil profile under generally high rainfall until 15 million years ago without landscape rejuvenation through tectonic activity. Thus, it is not surprising that nutrient content of the leaves of evergreen species here is also among the lowest in the world (Wright et al., 2004). Thus, leaves of hakeas and banksias have a $\mathrm{P}$ content of $0.025 \%$ and $\mathrm{N}$ content of $0.55 \%$ on average compared with the average for floras in the rest of the world of $0.10 \%$ and $2.5 \%$ respectively (Lamont et al., 2002; Witkowski \& Lamont, 1996; Wright et al., 2004). The low nutrient contents of the leaves is partly attributable to their high internal density because they are so sclerophyllous: mean LMA of $440 \mu \mathrm{g} \mathrm{mm}^{-2}$ versus mean for floras elsewhere in the world of $130 \mu \mathrm{g} \mathrm{mm}^{-2}$. That is, the nutrients are diluted by the high levels of structural material per unit volume of leaf.

Why are the trees and shrubs so sclerophyllous? In a low nutrient environment, an effective strategy is to have long-lived leaves so that absorbed inorganic nutrients can be re-used many times even when the metabolic rates are low. But the longer leaves survive the greater the chances that they will succumb to herbivores, drought, temperature extremes and wind buffeting. This is where the two components of leaf-mass-area as an index of sclerophylly become relevant. Incorporation of extra cellulose and lignin into the tissues increases rigidity of the leaf, improving support, preventing collapse during drought, reducing palatability and deterring herbivores directly via hardened edges and spiny teeth or apices (Figs. 3.4, 3.5, 9.3; Hanley et al., 2007). Just as cell walls are thickened so cells are smaller and the greater the ability to conduct sap through the leaf (Jordan et al., 2013). Thicker cuticles prevent water loss via the epidermis (cutin is hydrophobic) and they may even envelop the stomates.

Thickening the leaf increases light capture via the multilayed palisade, reduces transpiration rates by increasing resistance to movement of water from the xylem to the boundary layer, and increases its ability to store water in the central parenchyma and cell walls (Lamont \& Lamont, 2000). Deposits of calcium oxalate, silica, tannins, starch, the amino acid proline and anthocyanins increase with leaf age and supplement the ability of leaves to deter herbivores, resist pathogens and tolerate drought through osmotic adjustment (Richards \& Lamont, 1996). All may be involved in the greater survival of sclerophyllous species to abnormally high temperatures (Groom et al., 
2004). Increase in sclerophylly is accompanied by a reduction in leaf size associated with smaller cell size, vertical leaf orientation and conversion of dorsiventral leaves to isobilateral (stomates on both sides), frequently to a needle-shape (isolateral). These reduce the heat load on the leaf even when transpiration is negligible but allow photosynthesis to occur at the cooler time of day in warm weather when light is low on the horizon at dawn and dusk.
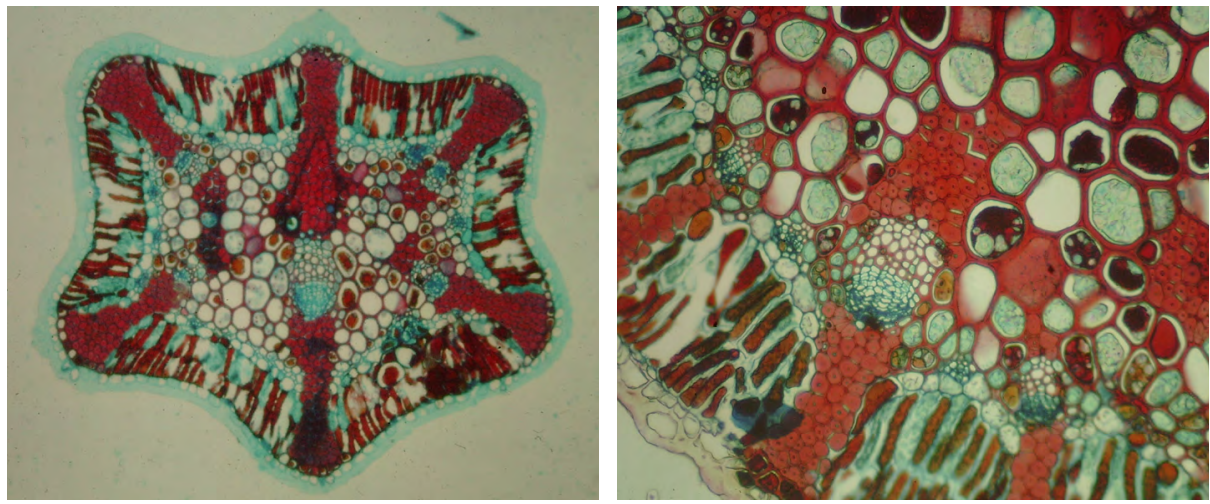

Fig. 9.3: The genus Hakea, with over 100 taxa in the SouthWest, contains the world's most sclerophyllous species (Wright et al., 2004). Pictured are tranverse sections of the needle leaves of (left) H. gilbertii and (right) H. subsulcata that are widespread in the wheatbelt and mallee regions of the SouthWest (Chapter 1). The sections have been treated with fast green that stains cellulose, cytoplasm and cutin green and phloem blue, and safranin that stains liginin and tannin red and cutin pink. Conspicuous are the 'girders' of lignified fibres that strengthen the leaf and prevent collapse of the delicate chlorophyll-bearing double palisade during severe drought. The girders are topped by a tannin-bearing hypodermis that restricts light uptake and hence the heat load on the most exposed ridged parts of the leaf (Jordan et al., 2005). There are also inner fibre groups wrapped around the vascular bundles that restrict water loss from the xylem. The inner parenchyma has walls thickened with lignin that increase the water-storing capacity of the leaf. Both the parenchyma and palisade have their vacuoles loaded with tannin that increases their osmotic concentration and assists in water retention through osmotic adjustment (Richards \& Lamont, 1996). The cuticle is 2-3 times thicker than the epidermal cells and it rises over the sunken stomates (completely covering the opening) to form epistomatal cavities, sometimes with mucilaginous plugs in the substomatal cavities, all serving to restrict water loss further. These features help to explain why leaf-mass-area, as an index of sclerophylly, is higher among hakeas the lower the rainfall in the SouthWest independent of the $\mathrm{N}$ and $\mathrm{P}$ contents of the leaves (Lamont et al., 2002).

In summary, the increasingly nutrient-impoverished soils in the SouthWest promoted the evolution of long-lived leaves. This was achieved through morphological and anatomical changes centred on sclerophylly that involved improved leaf support and herbivore and pathogen deterrence at first. Then, as plants became more exposed to light, heat and drought, and more efficient herbivores, as they moved out of dense forests over geological time, further structural and physiological changes evolved indicative of greater tolerance to high light and water deprivation. All these contributed 
to the extreme levels of scleromorphy present in the current flora, as LMA follows both nutrient gradients (Read et al., 2005) and rainfall gradients (Lamont et al., 2002) in the SouthWest. Spinescence also increases with decreasing rainfall effectiveness (B. Lamont, M. Hanley, P. Groom \& T. He, unpublished data).

\subsubsection{Case Study: Two Banksias with Long-Lived Leaves}

Banksia petiolaris (Proteaceae) is a ground creeper with large vertical leaves while Banksia baueri is a shrub with small horizontal leaves (Fig. 9.4). They co-occur in scrub-heath between Albany and Esperance with an annual rainfall of about $500 \mathrm{~mm}$. The sand-over-laterite substrate is nutrient-impoverished, with available $\mathrm{P}$ of only $2 \mathrm{ppm}$ (Witkowski et al., 1992). The leaves of B. petiolaris survive for up to 13 years and those of $B$. baueri for up to 5 years, both exceptionally long compared with nonsclerophyllous species. Leaf-mass-area (LMA) is similar in both species, except $B$. petiolaris leaves are $45 \%$ thicker than $B$. baueri, and $B$. baueri leaves are $40 \%$ denser than B. petiolaris. LMA in B. petiolaris increases from $250 \mu \mathrm{g} \mathrm{mm}^{-2}$ in the first year to $380 \mu \mathrm{g} \mathrm{mm}^{-2}$ in the eleventh year entirely due to an increase in leaf density over that time. Leaves of both species remain physiologically active throughout their long lives, maintaining strong control over their xylem water potentials, rates of transpiration and photosynthesis on a leaf area and nutrient basis, and water-use efficiency, though at low levels compared with non-sclerophylls, and lower still in the more sclerophyllous $B$. petiolaris, with all variables declining with leaf age.
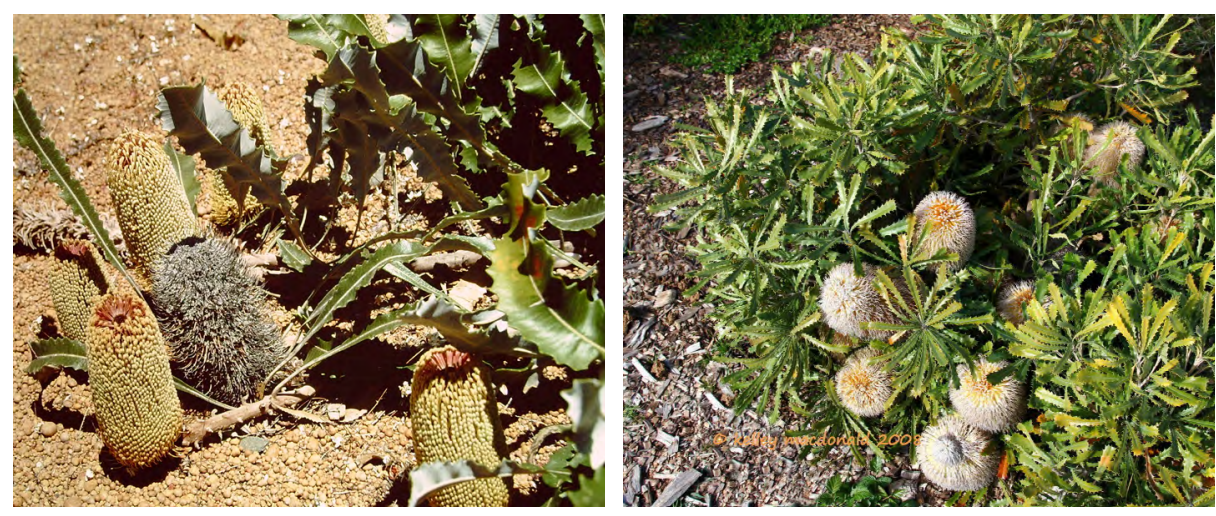

Fig. 9.4: (left) Banksia petiolaris showing its stoloniferous habit and erect leaves, $20-25 \mathrm{~cm}$ long, arising at ground level and known to survive for up to 13 years. (right) B. baueri is a $1.5 \mathrm{~m}$ tall shrub with $5-10 \mathrm{~cm}$ long leaves arranged at a slight angle to the horizontal that survive for up to 5 years apparently cut short by self-shading. Both species retain their dead florets and leaves that enhance plant flammability and ensure follicle opening and seed release, important as both species are killed by fire. 


\subsection{Leaf-like Structures}

Some genera do not produce true leaves, or they are highly reduced or modified. When the leaves are highly reduced, either the stem or the petiole takes on the photosynthetic function (Fig. 9.5). It is probably no accident that all the genera noted here contain above-average levels of nutrients in their foliage because of root adaptations to enhance nitrogen uptake (see Chapter 6) or are parasitic (Chapter 5), increasing their attractiveness to herbivores. All these modifications can be considered drought adaptations where survival is at the expense of growth rates.

1. Acacia (Fabaceae: Mimosoideae) - Adult leaves in this genus are typically either bipinnately compound (rare in SouthWest), phyllodinous, or reduced to scales. Phyllodes are expanded petioles that usually grow vertically rather than twist vertically as in true leaves. In some species (e.g. A. stenoptera) the phyllode continues down the stem to give a winged structure collectively called a phylloclade. In other species these are fasciculate (clustered or aggregated) (e.g. A. erinacea). Phyllodinous species are usually heteroblastic (Fig. 9.2), possessing compound leaves as seedlings that are soon replaced by phyllodes as the plant grows.

2. Daviesia (Fabaceae: Faboideae) - Phyllodes in this genus are either well developed, often spinescent, or are reduced to scales. When reduced to scales, branchlets (cladodes) then take over the photosynthetic function. Cladodes often end in a rigid, sharp point. Some species (e.g. D. horrida) produce phyllodes and cladodes on the same plant.

3. Jacksonia (Fabaceae: Faboideae) - Photosynthetic branchlets are flattened, angular or terete (= round in cross section) and often spinescent. Whereas adult leaves are reduced to scales, juvenile leaves are laminate and unifoliate (= a compound leaf appearing to be simple) when present. Other fabaceous genera (e.g. Bossiaea, Templetonia) also have species with reduced leaves and photosynthetic stems.

4. Allocasuarina and Casuarina (Casuarinaceae) - Outermost branchlets are the principle photosynthesising structure in this genus with the leaves reduced to whorled membranous scales. The green branchlets are sometimes called a cladode. Further, stomates are confined to grooves running along the stem (Chapter 3). The grooves close over as the stem dehydrates during drought, further restricting water loss.

5. Exocarpos and Leptomeria (Santalaceae) - Both these genera are root hemiparasites, possessing cladodes and leaves reduced to scales (in Leptomeria confined to species in Section Leptomeria of the genus). 

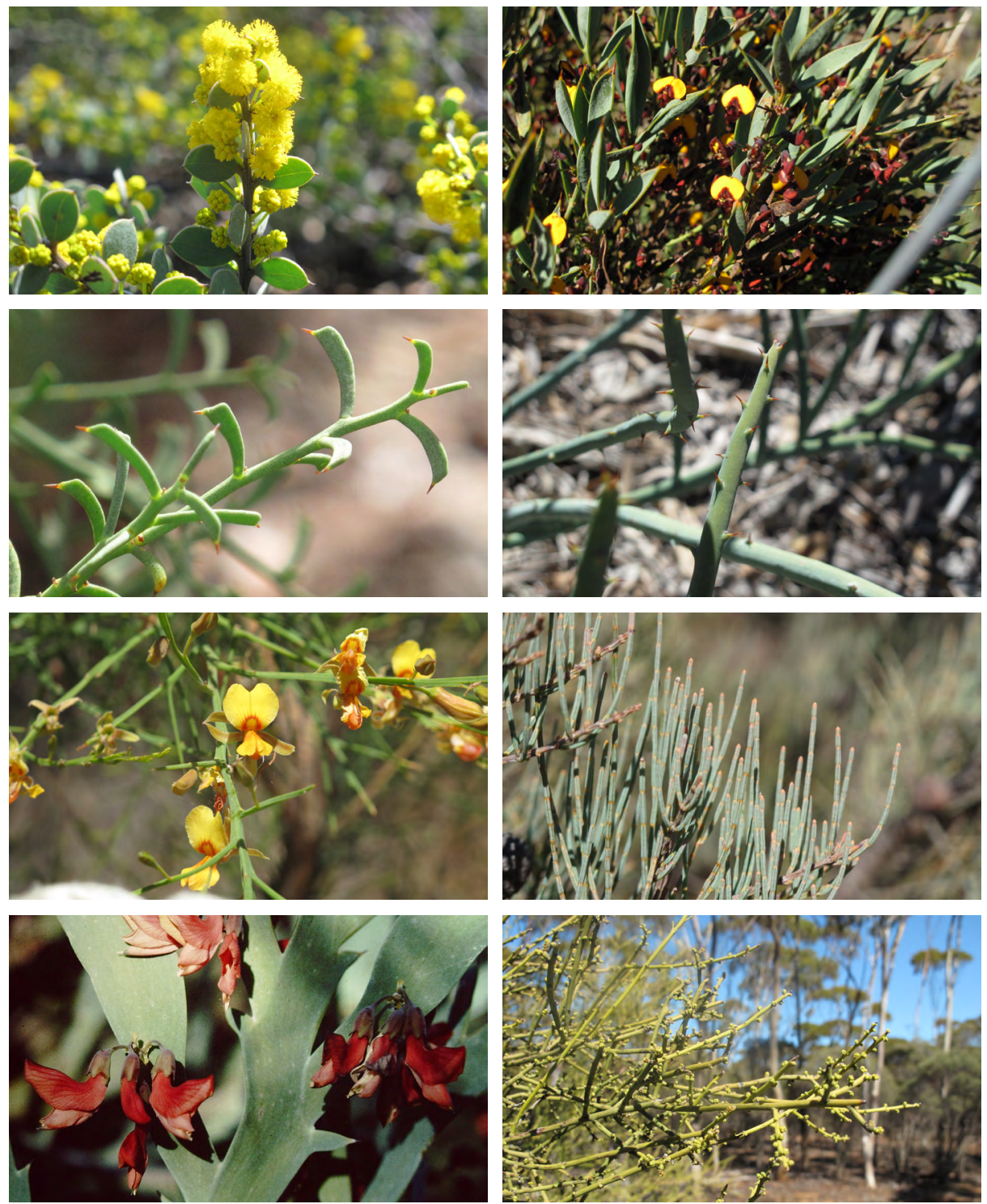

Fig. 9.5: Selection of leaf-like structures (from top to bottom): vertically-oriented 2-cm-long phyllodes (true leaves have to twist vertical whereas phyllodes grow vertically) of Acacia merrallii (Fabaceae); pungent phyllodes of Daviesia nudiflora (Fabaceae) $3 \mathrm{~cm}$ long and D. incrassata $2 \mathrm{~cm}$ long; $D$. euphorbioides has prominent photosynthetic cladodes, $7 \mathrm{~mm}$ wide, with phyllodes reduced to recurved spines; yellow-flowered Jacksonia sternbergiana (Fabaceae) with thorny cladodes $5 \mathrm{~cm}$ long; the genus Allocasuarina (Casuarinaceae) is characterised by cladodinous branchlets with leaves reduced to scales and occurring in whorls around the nodes, pictured here is $A$. humilis with 5-cm-long branchlets; the bird-pollinated Daviesia epiphyllum (Fabaceae) with its 40-mmlong flowers seemingly arising from its leaves (hence the specific name) that in fact are flattened cladodes with phyllodes, or phylloclades. Cladodes are also a common feature in the root parasitic genus Exocarpos (Santalaceae), pictured here is E. aphyllus, with 5-10 long branchlets. 


\subsection{Alternatives to Sclerophylly for Protecting Leaves}

Because the deposition of lignin and cellulose are time-dependent processes, young leaves are particularly vulnerable to herbivores, desiccation and scalding, especially as they are most exposed at the tips of the branches. Young leaves in many SouthWest evergreens are red due to the production of xanthophylls before the more nutrientdemanding synthesis of chlorophylls (Fig. 9.6). Since red reradiates in the 'hot' part of the light spectrum this can be expected to reduce the heat load on the leaf but experimental support is lacking. In contrast to mature leaves and leaves of adult plants that are more sclerophyllous and spinescent, young leaves and those on seedlings produce abundant phenolics that are effective against invertebrate herbivores (Hanley \& Lamont, 2002; Hanley et al., 2007). The young foliage of many species is covered in a dense indumentum of white or orange hairs (trichomes) that gradually abrade over time as the cuticle becomes much thicker. Other species retain their hair cover indefinitely giving a white, hoary appearance to the plant (Fig. 9.6). This pubescence is multifunctional, including increasing the saturated boundary layer to inhibit water loss, reflecting light and hence reducing the heat load, decreasing palatability and digestibility for herbivores, and deterring insects from ovipositing (Hanley et al., 2007). Many evergreens have a glaucous appearance due to the secretion of surface waxes (Fig. 9.6) that appear to function in a similar way to trichomes.

Glandular hairs that secrete resin (terpenoid/flavonoid mix) are well represented in SouthWest species of the families Boraginaceae, Fabaceae (subfamily Mimosoideae), Goodeniaceae, Lamiaceae, Scrophulariaceae, Sapindaceae and Solanaceae (Dell, 1977; Fig. 9.7). They are probably universal in Eremophila (Scrophulariaceae), a large genus lacking scleromorphy (malacophyllous) and well represented in the heavier soils of the driest parts of the SouthWest. These hairs need to be distinguished from the mucilagesecreting hairs of carnivorous plants (Chapter 4). Resin-secreting hairs are usually most abundant on leaves but may also occur on dormant buds (e.g. Banksia attenuata, though resin glands have yet to be observed), young stems (e.g. Grevillea eriostachya), inflorescences (e.g. Grevillea leucopteris) and the lower parts of flowers (e.g. Calytrix glutinosa, Myrtaceae). These resins are viscous at first and flow over the surface and may contribute $15-20 \%$ of the dry weight of mature leaves (Dell \& McComb, 1974, 1975). They often harden to form a varnish over the surface making it shiny and greatly increasing reflectance of all parts of the visible spectrum (Dell, 1977) and thus reducing heat load on the leaf. They are hydrophobic and must also act in a similar way to cutin in reducing water loss via the epidermis. Glandular hairs associated with flowers are sparser and the resin remains viscous without forming a sheet. They are more likely to have an antiherbivore function here by deterring and capturing insects in general and reducing palatability. Many Stylidium species possess glandular hairs on their stems and parts of inflorescences and flowers not directly related to reproduction but they appear to be mucilaginous rather than resinous (Darnowski et al., 2006). They are rarely seen to capture insects and light reflection is not obvious so their function is unclear. 

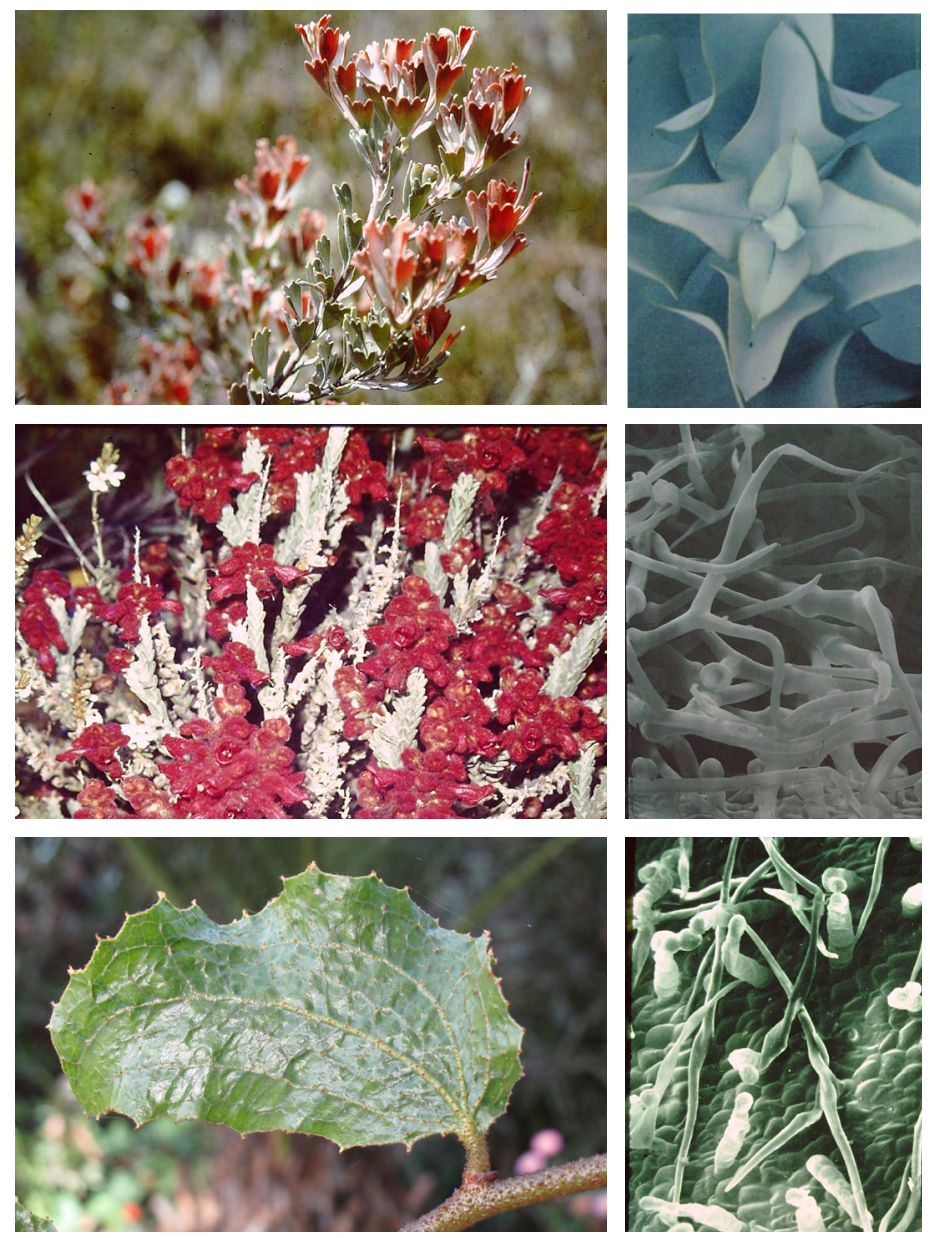

Fig. 9.6: Leaf surface features. (upper left) Young foliage of Adenanthos cuneatus (Proteaceae) is red and covered in a fine indumentum of hairs that is still present on mature leaves, $3 \mathrm{~cm}$ long, giving them a hoary appearance. Note their vertical orientation. (upper right) The entire shoot system (apart from the oldest basal stems) of Eucalyptus macrocarpa (Myrtaceae) is covered by a waxy glaucous bloom that is densest on the youngest leaves. Apical bud $2 \mathrm{~cm}$ wide. (middle left). Hemiphora elderi (Lamiaceae), $50 \mathrm{~cm}$ tall, not only has a dense indumentum over its leaves giving the plant a hoary appearance but also woolly flowers covered with deep-red, stellate hairs. (middle right) Verreauxia reinwardtii (Goodeniaceae) has 2-mm-thick, white wool over the entire plant. When examined under the electron microscope, the intricate structure of its stellate hairs are revealed with the tips of opposing branches fused by 'plugs' and short glandular hairs near the epidermis. Scale $=100 \mu \mathrm{m}$. (lower left) Acacia denticulosa (Fabaceae) showing a vertically-oriented phyllode, $6 \mathrm{~cm}$ long, covered in resin exuded by tuberculate glands over both (isobilateral) surfaces and giving it a highly reflective appearance. (lower right) Surface of young leaves, inflorescences and stems of Grevillea leucopteris (Proteaceae) are covered in both T-shaped hairs (a common feature of hakeas and grevilleas) and simple glandular hairs, $50 \mu \mathrm{m}$ tall, that secrete resin. These hairs capture a wide variety of insects but whether they have any role in deterring herbivores, such as lepidopteran larvae, is unknown. With respect to possible carnivory, the average capture of 50 insects per $100 \mathrm{~cm}$ of branch length would only meet $0.15 \%$ of the nitrogen requirements of the plant even if fully released (Lamont, 1982c). 


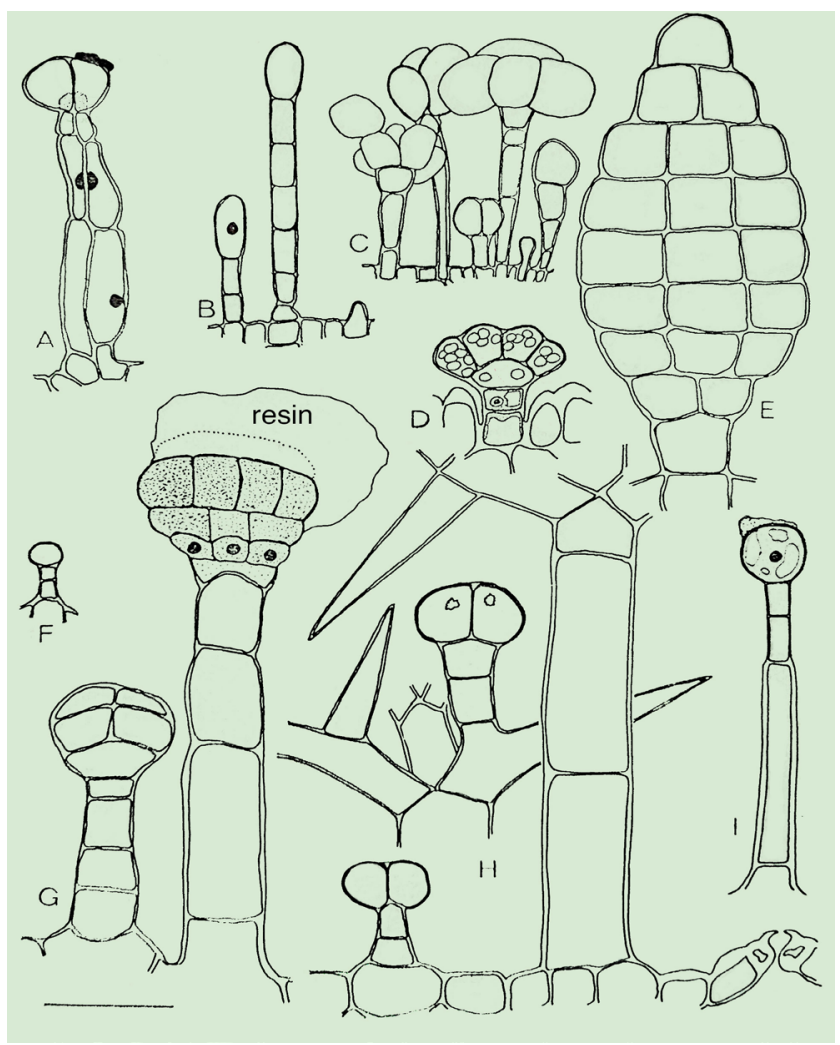

Fig. 9.7: Line drawings of glandular hairs (some bearing globs of resin) on leaves and stems with shiny or sticky surfaces due to the resin they produce flowing over the epidermis and reducing water loss and the summer heat load. A. Helichrysum rosea (Asteraceae), B. Grevillea eriostachya (Proteaceae), C. Acacia aneura (Fabaceae), D. A. glutinosissima, E. Anthocercis littorea (Solanaceae), F. Scaevola crassinervia (Goodeniaceae), G. Scaevola glandulifera, H. Eremophila leucophylla (Scrophulariaceae) (note stellate hairs may also be glandular and presence of raised surface stomates, usually a feature of mesophytes, that prevents resin flowing into pore and clogging it), I. Pityrodia bartlingii (Lamiaceae). Scale $=50 \mu \mathrm{m}$. From Dell (1977) and used with permission from the Royal Society of Western Australia.

\subsection{Leaves as Defensive Mechanisms Against Herbivores, Florivores and Granivores}

Most leaf herbivores in the SouthWest are insects, marsupials (e.g. possums, kangaroos), emus and introduced fauna (e.g. mainly rabbits). Leaves can display a number of structural defences to deter or reduce herbivory, including sharply-pointed spines and hardened leaf margins, hairs and tough (sclerophyllous) leaves (Fig. 9.8) (Hanley et al., 2007). Within a species, seedling leaves often possess chemical 
deterrents to herbivores while mature plants are more likely to rely on physical deterrents, such as high LMA and spines (Rafferty et al., 2005; 2010).

The production of distasteful or toxic compounds (e.g. phenolics, alkaloids, essential oils) as chemical defences is an alternative means of deterring herbivores. This may occur as a trade-off with structural traits, as for example within the genus Gastrolobium (Fabaceae) (Twigg \& Socha, 1996). Highly spinescent and sclerophyllous Gastrolobium species (Fig. 9.8) tend to have lower leaf concentrations of the toxic chemical, sodium fluoroacetate, than less spiny, softer leaved species. Because all native vertebrate herbivores have evolved a natural tolerance to fluoroacetate, the commercial preparation known as $10-80$ can be used in baiting programs to control feral cats and foxes.
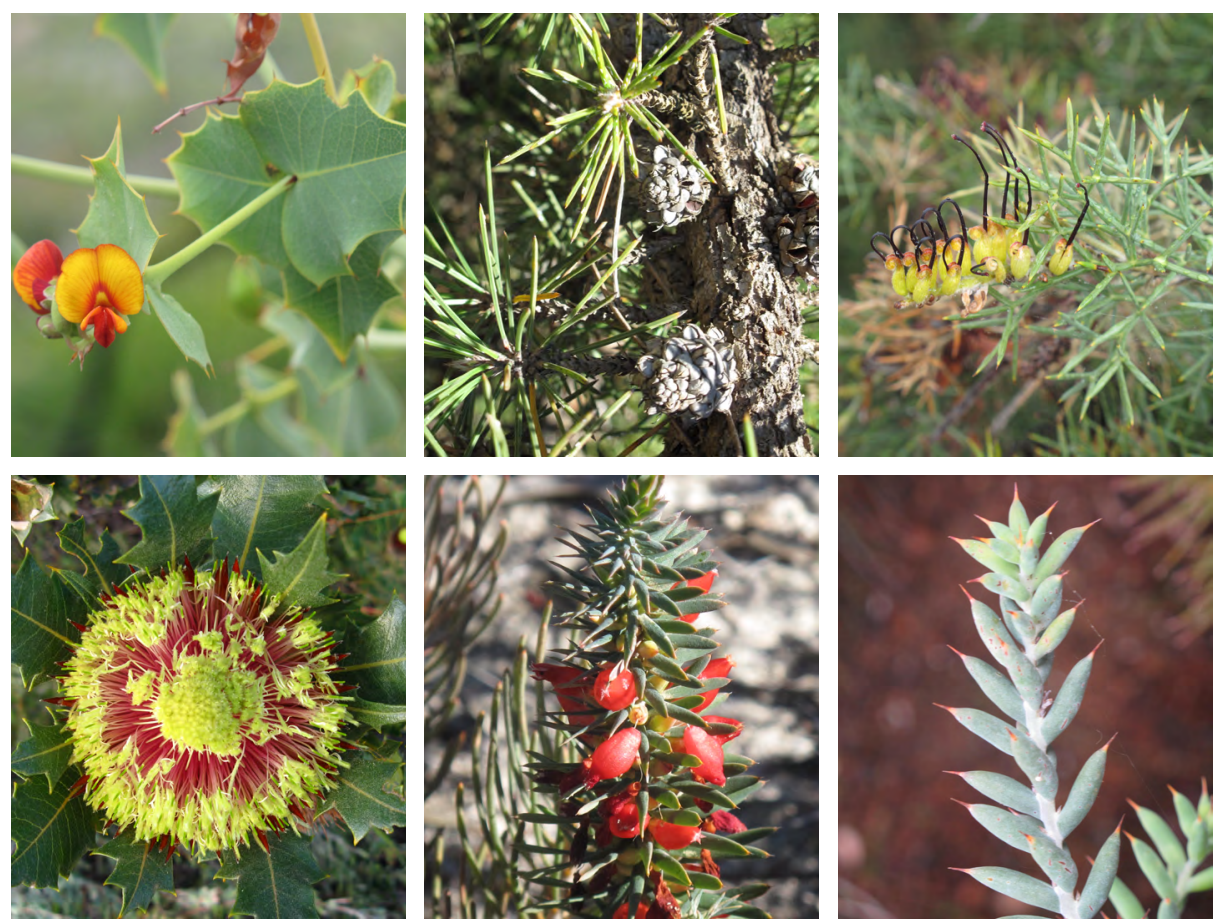

Fig. 9.8: Sclerophyllous and spinsecent leaves of Gastrolobium spinosum (Fabaceae), leaves $4 \mathrm{~cm}$ long. (upper middle) Allocasuarina pinaster (Casuarinaceae), pungent cladodes $5 \mathrm{~cm}$ long. (upper right) Grevillea hookeriana subsp. hookeriana (Proteaceae), pronged terete leaves $3 \mathrm{~cm}$ long. (lower left) Banksia heliantha (= Dryandra quercifolia) with serrated leaves, flower head $10 \mathrm{~cm}$ diameter. (lower middle) Astroloma glaucescens (Ericaceae), leaves $2 \mathrm{~cm}$ long. (lower right) Daviesia pachyphylla (Fabaceae), commonly known as the ouch bush, because of the relatively long and sharplypointed mucro at the tip of the phyllode $(2.5 \mathrm{~cm}$ long). 
Anti-herbivory traits may also be effective against florivores (flower eaters). Work on the genus Hakea (Proteaceae) (Hanley et al., 2009) shows that insectpollinated species (e.g. H. costata) (Fig. 9.9) tend to have small-flowered inflorescences either subtended by sharply pointed leaves or surrounded by dense sclerophyllous foliage. In contrast, bird-pollinated species (e.g. H. francisiana, Fig. 9.9) have inflorescences that are highly accessible, usually red in colour (See Chapter 8), and contain higher levels of floral cyanoglycosides (cyanide-based compounds) that deter florivores. The red floral coloration not only attracts visually cued pollinators (e.g. honeyeater birds) but is also a warning that the infloresecences are unpalatable.
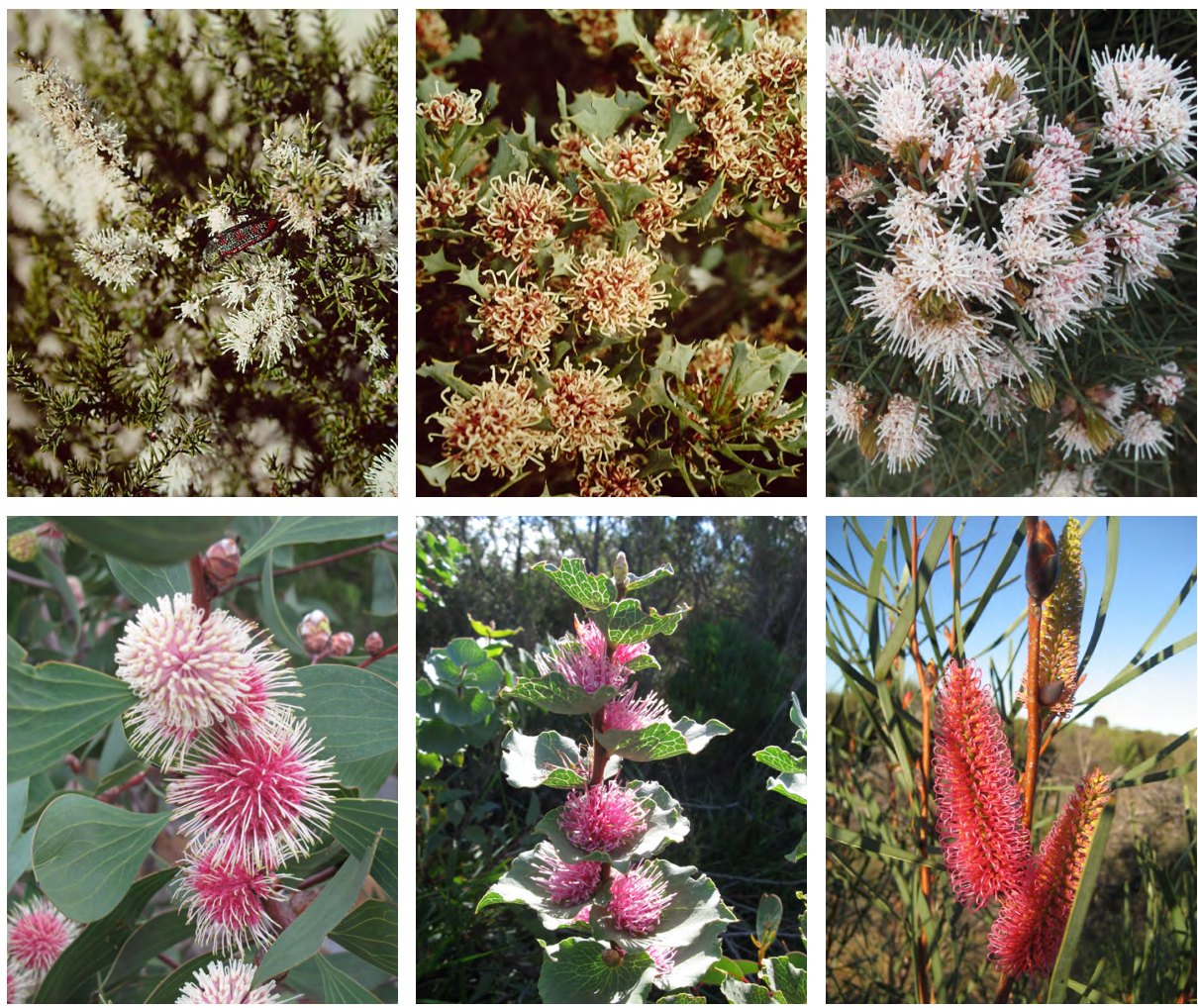

Fig. 9.9: (upper) insect-pollinated Hakea species (from left to right) $H$. costata (with 15 -mm-long Stigmodera (jewel) beetle pollinator), $H$. spathulata with 3-cm-wide axillary clusters and $H$. gilbertii with 2-cm-wide clusters. (lower) bird-pollinated Hakea species: H. petiolaris with 5-cm-wide clusters often produced on old stems (cauliflory), H. cucullata with $5-\mathrm{cm}$-wide cluster - the subtending leaves act as landing platforms and $H$. francisiana with $15-\mathrm{cm}$-long racemes. Note how the dense, spiny foliage of insect-pollinated species will deter avian florivores but bird-pollinated species have strong stems that also allow avian florivores, such as cockatoos, to land. However, these flowers contain high levels of toxic, cyanide-yielding compounds and there is a strong correlation between bright pink/red and the presence of cyanogens. 


\subsubsection{Cryptic Mimicry}

Hakea trifurcata (Fig. 9.10) produces different types of leaves on the same branch (i.e. heterophylly): some are needle-like while others are broad and recurved. Instead of turning brown, mature woody fruits retain their green coloration. In turn, the broad leaves produced at the same axils as the fruits superficially resemble the fruits, their inrolling giving them a solid appearance. Studies have shown that this similarity confuses potential seed eaters, such as Carnaby's black cockatoo, and greatly reduces seed predation. Until they reach reproductive maturity, the juvenile plants only produce needle leaves. This unusual form of mimicry within a species is termed selfcrypsis (Groom et al., 1994). The broad leaves are often significantly larger than the fruits, and hence may also hide or shield the fruits from visually-cued granivorous birds.

Similar mimicry occurs within the trifurcata (H. trifurcata, H. lasiantha, H. lasianthoides) and prostrata (Hakea prostrata, H. denticulata, H. pritzelii, H. amplexicaulis) groups (Fig. 9.10; 9.11) all producing green fruits, sometimes with spiny or toothed appendages that mimic the surrounding leaves. The fruit walls are often the least woody among all hakeas, and the seeds are only retained in the crown for a year or so. The fruits of $H$. stenocarpa are brown, long, thin and gnarled and appear to resemble branchlets and the dead, strap-like leaves (that are retained). H. ruscifolia fruits are not only embedded among compact outward-facing leaves that have an extremely sharp mucro at the tip but they remain green and are a similar size and shape as the leaves.

\subsubsection{Fruits Hidden by Leaves}

Hakea polyanthema (Fig. 9.10; 9.11) has its woody fruits positioned deep within a 'nest' of outward projecting, sharply pointed, needle leaves, and creates an impregnable barrier, ensuring that the fruits remain inaccessible to potential granivores or insects attempting to lay eggs on the fruit surface. This is a feature of many spinescent hakeas in the SouthWest (e.g. Hakea auriculata; Fig. 9.10).

The cup or shell-like leaves of Hakea conchifolia and H. smilacifolia and undulating stiff leaves of $H$. victoria hide the fruits from granivores (Fig. 9.10; 9.11), decreasing the likelihood of seed loss, either from strong-billed cockatoos or seed-eating insect larvae. 

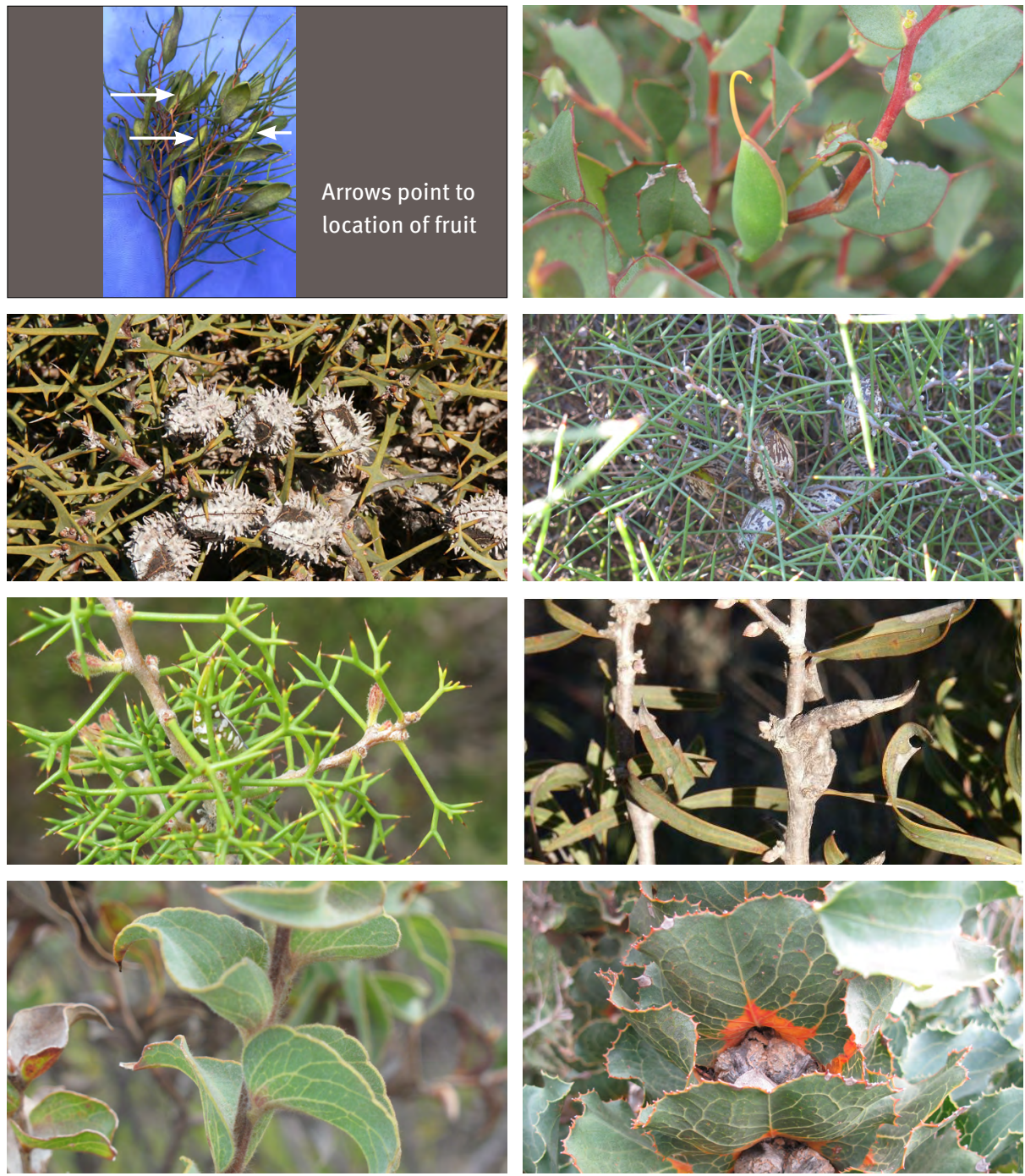

Fig. 9.10: A selection of leaf-based strategies that minimise granivory in Hakea. (upper left) A heterophyllous branchlet of $H$. trifurcata. Arrows point to the woody fruits that remain green at maturity. Their shape and size resemble those of the surrounding broad leaves. Fruit $18 \mathrm{~mm}$ long. (upper right) Developing fruit (centre) of $H$. denticulata mimics the surrounding leaves in terms of coloration and marginal spines. Fruit $25 \mathrm{~mm}$ long. (upper middle left) $H$. auriculata with its 25 - $\mathrm{mm}$-long fruits enmeshed among extremely spinescent leaves. The unique prickles and brown markings on the fruits might have camouflage significance as well. (upper middle right) The mottled fruits of $H$. polyanthema embedded in an impenetrable nest of sharply-pointed, terete leaves. Fruits $25 \mathrm{~mm}$ long. (lower middle left) Mottled $H$. erinacea fruit partially camouflaged among its sharply-pointed, highly-divided, terete leaves. Fruit $20 \mathrm{~mm}$ long. (lower middle right) $H$. stenocarpa with four gnarled, elongated, 4-cm-long fruits that might be mistaken for branchlets or dead leaves by potential granivores. (lower left) Cup-shaped leaves of $\mathrm{H}$. smilacifolia surround and conceal their small, thin-walled fruits from avian granivores. Leaf $30 \mathrm{~mm}$ long. (lower right) Woody fruits of $H$. victoria are well concealed by their subtending large, sharply-margined leaves. Leaves can be $15 \mathrm{~cm}$ wide. Photograph taken at an angle to the plant so that fruits are visible. 

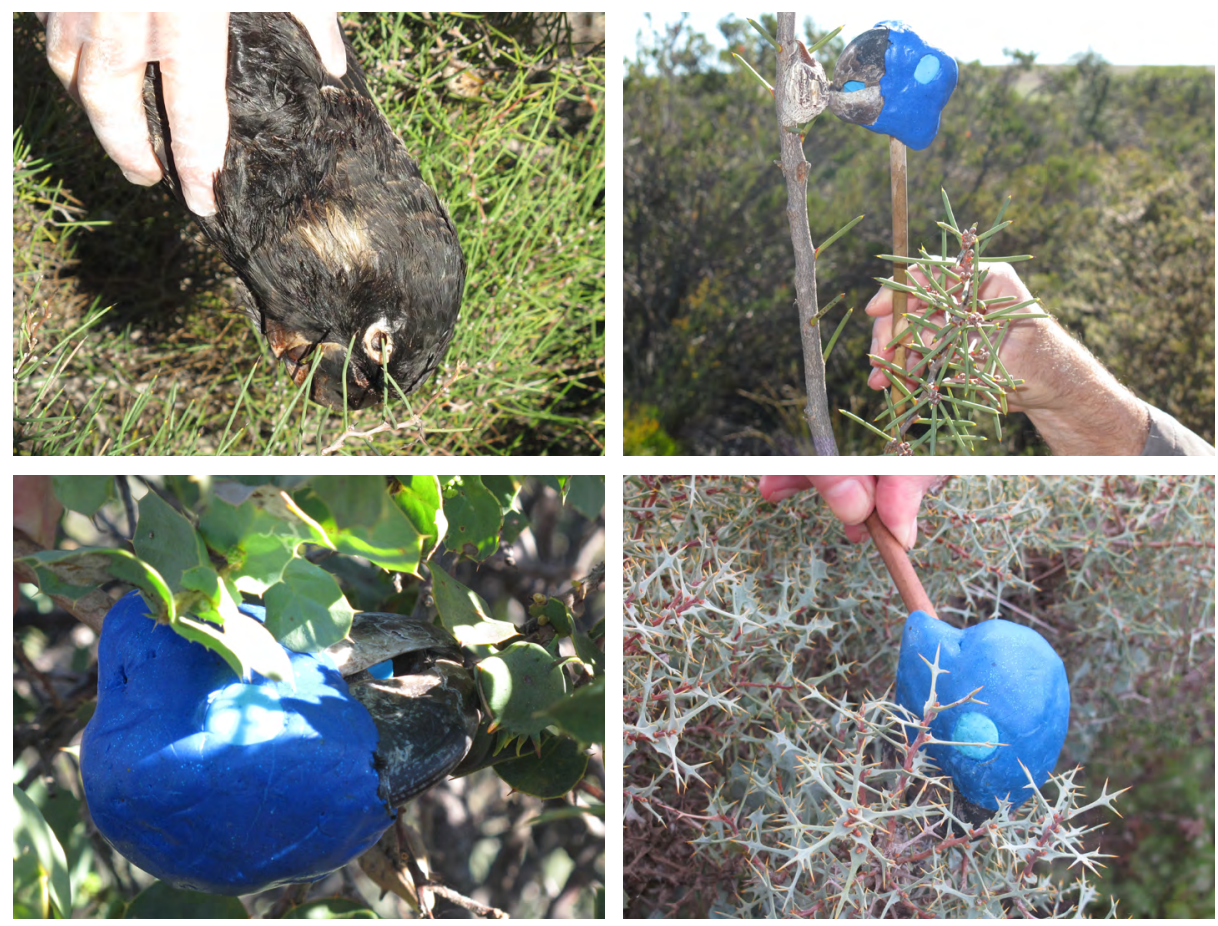

Fig. 9.11: Using a mummified Carnaby's black cockatoo and a recreated head using a skull and blue moulding clay to demonstrate how the spinescent leaves of selected Hakea species may deter avian granivores from attacking the woody fruits. Species are (upper left) $\mathrm{H}$. polyanthema. Note that the pointed leaves are pressing against the bird's eye and beak. (upper right) H. psilorrhyncha. Despite possessing sharply-pointed, stiff leaves, the fruits of this species are sometimes easily accessable to cockatoos but they are especially large and woody. (lower left) H. prostrata. Leaves have sharp marginal spines, plus the fruit (pictured at the tip of the beak) resembles the surrounding leaves. (lower right) H. auriculata. This species is heterophyllous with the leaves associated with flowering (protecting the inflorescences as well as the fruits) are narrower and three-pronged at the apex, compared with the leaves not associated with flowering.

\subsubsection{Herbivore Defence Among Restios}

The Restionaceae (wire rushes) is a major herbaceous family in the SouthWest flora. Species have wiry green stems (culms) with leaves reduced to dry scales at the nodes. These are a poor food source for herbivores, averaging $0.57 \% \mathrm{~N}$ and $0.02 \% \mathrm{P}$, and high in fibrous tissues and tannins (Meney \& Pate, 1999). Nevertheless, any plant that is grass-like in form is favoured by kangaroos and wallabies, and restios are often heavily browsed. However, 16 species of Lepyrodia and five species of Loxocarya produce a rare sulphur-containing amino acid, S-methyl cysteine, that strongly inhibits browsing by kangaroos and grasshoppers (Pate et al., 1995). 